\title{
ПРИРОДНЫЕ И АНТРОПОГЕННЫЕ ФАКТОРЫ, ОБУСЛОВЛИВАЮЩИЕ АКТИВНОСТЬ СКЛОНОВЫХ ПРОЦЕССОВ ТЕРРИТОРИИ ПРОЕКТИРУЕМОЙ ЖЕЛЕЗНОЙ ДОРОГИ ЭЛЕГЕСТ-КЫЗЫЛ-КУРАГИНО
}

\author{
Строкова Людмила Александровна 1 , \\ sla@tpu.ru
}

\author{
Надеждина Юлия Юрьевна 1 , \\ levak.yuliya@mail.ru \\ 1 Национальный исследовательский Томский политехнический университет, \\ Россия, 634050, г. Томск, пр. Ленина, 30.
}

\begin{abstract}
Актуальность исследования обусловлена разработкой проекта первой железной дороги в Тыве, которая должна связать Тыву с Красноярским краем. Трасса планируется в сложных инженерно-геологических условиях. В статье представлена оценка инженерно-геологических условий территории трассы, необходимая для поддержки процесса принятия решений по размещению сооружений.

Целью данного исследования является изучение влияния природных и антропогенных фракторов на активность склоновых процессов на территории, таких как обвалы, подвижные осыпи, лавины, солифрлюкция, каменные глетчеры, курумы, сплывы, сели. Объектом исследования является геологическая среда района проектируемой трассы Кызыл-Курагино. Рассмотрены основные фракторы, влияющие на формирование склоновых процессов: геоморфологические и тектонические условия; литологический состав; физико-механические свойства пород, гидрологические, гидрогеологические и мерзлотные условия района, экзогенные и эндогенные геологические процессы, наличие автодорог. Каждый фрактор далее подразделяется на классы.

Методы. Для определения взаимосвязи между природными и антропогенными фракторами и активностью склоновых процессов использован статистический анализ частотности склоновых процессов и метод анализа иерархий наряду с географической информационной системой.

Результаты. Для определения взаимосвязи природных и антропогенных факторов со склоновыми процессами было проанализировно 9 факторов с 43 классами внутри них. Обнаружено, что наиболее значимыми параметрами являются: уклон поверхности, ее высотная отметка, экспозиция склона, генетический тип и литологический состав грунтов. Частота гравитационных смещений увеличивается на северных склонах с уклоном более $10^{\circ}$, с отметками более 2000 м, сложенных метаморфическими породами и обломочными образованиями. Частота и масштабы оползней увеличиваются в непосредственной близости от дорог. Их максимальные значения наблюдаются в пределах 50-метровой буферной зоны. Результаты определения весов двумя методами показали высокую сходимость результатов.

Выводы. Результаты дают информацию о природных и антропогенных фракторах, характеризующих склоновые процессов на исследуемой территории. Применяемая методология позволяет оценить участки, предрасположенные к склоновым процессам, откартировать их, и может быть использована для составления документации по планировке и разработке рекомендаций по инженерной защите территории.
\end{abstract}

\section{Ключевые слова:}

Грунты, склоновые процессы, географическая информационная система, метод соотношения частотностей, метод анализа иерархий.

\section{Введение}

Строительство железной дороги КурагиноКызыл-Элегест будет способствовать развитию производственного комплекса и экономики Тывы. Строительство дороги длиной в 412 км будет осуществляться в крайне сложных инженерно-геологических условиях через хребты Западного Саяна. Слабая изученность инженерно-геологических условий региона из-за труднодоступности местности, суровости климата повышает значимость инженерногеологического изучения района. Технология выполнения таких работ в горной местности подробно изложена в работах [1-22].

Цель работы изучить распространение склоновых процессов на территории проложения новой железной дороги. Поставленная цель обусловила решение следующих задач: разработать методику и критерии инженерно-геологического анализа предрасположенности территории к склоновым процессам в среде ГИС; выявить особенности пространственной диффе- ренциации и динамики геологических тел региона; создать базу геоданных для анализа динамики природных условий; по данным ГИС-анализа выполнить оценку предрасположенности территории к проявлению склоновых процессов.

Исследование, проведенное в отделении геологии ТПУ, включало анализ литературных и фондовых материалов, полученных при инженерно-геологических изысканиях отдельных участков трассы в 2009-2019 гг.; их обобщение и анализ. Научная значимость исследования состоит в том, что получены новые результаты (новые знания) о пространственной дифференциации и динамике геологических тел региона, определен оптимальный набор параметров геологической среды, выполнено их ранжирование для оценки предрасположенности территории к развитию склоновых процессов. Практическая значимость заключается в использовании результатов для обоснования выбора трассы новой железной дороги, для рационального природопользования. 


\section{Характеристика инженерно-геологических условий района}

Основные особенности любой территории обусловлены совокупностью геологических процессов, реализованных в ходе истории геологического развития территории, ее тектоническим строением.

В тектоническом отношении зона предполагаемой трассы находится в центральной части АлтаеСаянской области, относится к типу мозаичноблоковых и представляет собой коллаж разновозрастных и разнотипных сооружений $[23,24]$ :

- палеомикроконтинентов - добайкальских массивов на юго-востоке (Сангиленская глыба) и островодужно-офиолитовых поясов (Куртушибинский, Борусский, Западно-Тывинский, Северо-Саянский);

- пассивных континентальных окраин палеокеанов: салаирских складчатых систем - на северо-востоке (Восточносаянская), востоке (ВосточноТывинская), на юго-востоке (Верхне-Енисейская); каледонских - на западе и юго-западе (Западносаянская-Тывинская система);

- ареалов проявления коллизионного интрузивного магматизма;

- наложенных структур позднепалеозойской, мезозойской активизации и кайнозойского рифтогенеза, выраженных морфологически в виде впадин, прогибов и линейных зон деформаций, линейных ареалов малых интрузий, роев даек и излияний базальтов.

Большую роль в разграничении структур играют глубинные (мантийные) и региональные разломы.

В геоморфологическом отношении территория трассы характеризуется большим разнообразием. Здесь распространены высокогорные (более 2000 м), среднегорные хребты с абсолютными отметками $1000 . .2000$ м, низкогорные - до 1000 м, а также аккумулятивные и денудационные равнины меж- и внутригорных впадин с высотами поверхности $300 \ldots 700$ м.

Геокриологические условия. Важной особенностью этой территории является широкое и чрезвычайно пестрое распространение сезонной мерзлоты и многолетнемерзлых пород (ММП).

Пояс сплошного распространения ММП представлен в наиболее приподнятых горных массивах либо отдельных вершинах хребтов на высотах 2000 м и выше. Мощность ММП 200-400 м со среднегодовой температурой от -3 до $-5^{\circ} \mathrm{C}[25]$.

Пояс прерывистого распространения ММП представлен в интервале высот 1500-2000 м. Мощность мерзлой толщи горных пород изменяется до 100 м, реже до 300 м со среднегодовой температурой от 0 до $-2{ }^{\circ} \mathrm{C}$.

Островное распространение ММП представлено широкой полосой в нижней части хребтов Восточного Танну-Ола, хребта Обручева, почти полностью охватывает Тоджинскую и Туран-Уюкскую впадины и в незначительной мере - Тывинскую депрессию. В горах островная мерзлота развита в интервале высот $1000 \ldots 1500$ м в зависимости от экспозиции склонов, литологического состава грунтов, их влажности, почвенно-растительного покрова. В котловинах мерзлота обнаруживается на высоте $500 . .900$ м. Мощность
ММП незначительная, в горах $10 \ldots 30$ м, на дне котловин $-5 \ldots 15$ м, редко 30 м. Средняя многолетняя температура колеблется от 0 до $-1,5{ }^{\circ} \mathrm{C}$.

Пояс редкоостровной многолетней мерзлоты представлен в степных и полупустынных ландшафтах Тывинской котловины, на склонах окружающих их хребтов в интервале высот 600...1200 м. Среди талых пород в пониженных частях котловин встречаются редкие острова многолетнемерзлых пород и перелетки.

Пояс сезонного промерзания пород представлен в ландшафтах Южно-Минусинской котловины.

Характер ММП и сезонной мерзлоты в разных ландшафтно-геоморфологических условиях региона определяет развитие криогенных процессов. На плоских водораздельных поверхностях и склонах высокогорий мерзлотные процессы представлены нагорными террасами, курумами, криоструктурными и солифлюкционными образованиями [25-28]. В днищах межгорных котловин широко развиты морозобойные трещины, бугры пучения, наледи и термокарстовые просадки и наледеобразование.

В гидрогеологическом отношении территория трассы располагается в границах единой гидрогеологической Алтае-Саянской складчатой области, представляющей собой сложную систему гидрогеологических массивов (Восточно-Саянский, Западносаянский и Восточно-Тывинский) и межгорных бассейнов. В пределах последних выделены Южно-Минусинский, Усинский, Улуг-Хемский адартезианские бассейны с различной обводненностью, минерализацией [23, 24].

Гидрогеологические массивы, сложенные осадочными и метаморфическими породами докайнозойского возраста и интрузивными породами, содержат трещинно-поровые воды зоны трещиноватости скальных пород, трещинно-карстовые воды в районах развития карбонатных разностей и трещинножильные воды зон тектонических нарушений. Наиболее развиты по площади воды зоны приповерхностной трещиноватости, часто имеющей мощность не более 100 м. Трещинно-жильные воды, приуроченные к зонам тектонических нарушений, часто выходят на поверхность в виде восходящих родников.

Артезианские бассейны приурочены к межгорным впадинам, выполненным рыхлыми кайнозойскими отложениями, в меньшей мере формациями мезозоя. В долинах крупных рек водоносные горизонты мощностью 2...7 м приурочены к аллювиальным пескам и галечникам, глубина их залегания изменяется от $0,5 \ldots 8$ м на поймах до $5 \ldots 12$ м на низких террасах и до 15 м на средних и высоких террасах. Подземные воды озёрно-аллювиальных отложений приурочены к песчано-гравийно-галечниковым пачкам, залегающим на глубине $10 \ldots 25$ м. Часто они имеют спорадический характер, во многих случаях обводнены незначительно. Подземные воды аллювиальнопролювиальных образований, слагающих предгорные шлейфы и конусы выноса, встречаются на глубине $5 \ldots 50$ м. Водоносность пород крайне неравномерна, преобладают слабоводоносные породы [23, 24]. Важные особенности подземных вод региона изучены недостаточно и неравномерно. 
Состав и физико-механические свойства изучены по 5965 пробам грунтов и 1027 образцам скальных пород, отобранных в результате бурения 2418 инженерно-геологических скважин в 2012-2017 гг. Характеристика состава и физико-механических свойств грунтов приведена в [29].

\section{Методика выполнения работ}

Определение пространственных закономерностей распространения геологических опасностей выполнено по технологии изучения и картографирования предрасположенности территории к развитию экзогенных геологических процессов (ЭГП), описанной в работах [30-60]. Изучение восприимчивости осуществляется в следующей последовательности. Вначале выполняется подготовка тематических слоев, таких как: карта проявления ЭГП (инвентаризационная карта); количество выпадающих осадков; литология; геоморфология; гидрогеология; цифровая модель рельефа, с которой можно установить абсолютные отметки рельефа, угол склона, экспозиция и других факторов, обуславливающих возникновение ЭГП и интенсивность их развития. Поскольку значимость каждого фактора в зависимости от региональных геологических, морфометрических, климатических, техногенных условий в общей оценке разная, необходимо выполнять оценку веса каждого фактора. Такая оценка выполняется с помощью различных статистических и детерминированных подходов. В данной работе для определения веса каждого фактора использовался метод соотношения частотностей (frequency ratio, FR) и анализа иерархий (AHP).

Метод анализа иерархий (Analytic Hierarchy Process, AHP)

Метод анализа иерархий, предложенный Т.Л. Саати в 1970 г., является относительно простым и эффективным методом в определении веса факторов [50]. Преимушество метода заключается в том, что он позволяет количественно оценить критерии и варианты, которые затруднительно или вовсе невозможно измерить точными измерениями [41-44]. Решение проблемы методом АНР заключается в представлении проблемы в виде иерархической структуры, объединяющей цель выбора, критерии, альтернативы и другие факторы, влияющие на выбор решения.

Применение метода состоит из пяти основных действий:

1. Определение непосредственной задачи (проблемы) и критериев (факторов) оценки. Любую задачу можно подразделить на иерархию связанных подзадач (более мелких проблем). Установление критериев оценки носит субъективный характер.

2. Определение альтернатив, которые будут оцениваться. Под альтернативами понимаются характеристики или свойства оцениваемого в данном случае геологического процесса. Итогом этого шага является подготовка перечня альтернативных критериев, по которым необходимо провести оценку.

3. Попарное сравнивание критериев (факторов), выбранных для оценки. В процессе сравнения необходимо определить, во сколько раз альтернатива «1» оказывает большее влияние на развитие про- цесса, чем альтернатива «2». Например, насколько геологическое строение склона важнее его экспозиции и т. д. При сравнении пары факторов остальные в этот момент в учет не принимаются.

4. Определение непосредственно веса критериев по шкале Т. Саати, согласно которой вес критериев выражается в числовом диапазоне от 1 до 10, где каждому значению присваивается словесная характеристика, например, «сильная значимость», «одинаковая значимость», «слабая значимость» и другие. Аналогично попарное сравнение проводится внутри каждого фактора по классам.

5. Проверка согласованности сравнения критериев путем расчета индекса согласованности, значение которого не должно превышать $10 \%$.

\section{Метод соотношения частотностей (frequency ratio, FR)}

Метод соотношения частотностей (FR) относится к статистическим методам, применяемым при оценке подверженности территории склоновым процессам [45-47]. Метод FR основан на выявлении корреляционной связи между пространственным положением процесса и факторами, его обусловливающими (причинными факторами).

Метод реализуется путем создания моделей ГИС и цифровой базы данных. Математически метод соотношения частотностей осуществляется по формуле:

$$
F R=\frac{N_{i}^{P} / N}{N_{i}^{l p} / N^{l}},
$$

где $N_{i}^{P}$ - площадь распространения границ действия оцениваемого фактора; $N_{i}^{l p}-$ площадь распространения склоновых процессов в границах действия оцениваемого фактора; $N$ - общая площадь исследований; $N^{l}$ - площадь распространения склоновых процессов на всей площади исследования.

На первом этапе рассчитываются площади классов каждого фактора и их доли (\%) от площади исследуемого района. Далее в пределах каждого класса определяются площади проявления ЭГП (в км² и \%), а также отношение доли площади проявления ЭГП к доле площади самого класса (вес FR).

\section{Результать}

Для оценки склоновых процессов, таких как обвалы, подвижные осыпи, лавины, солифлюкция, каменные глетчеры, курумы, сплывы, сели, была подготовлена серия тематических карт по каждому фактору, их обусловливающих (рисунок). Выбор факторов предопределен спецификой местности, а именно преобладанием в районе исследований высокогорной зоны. Общая площадь исследуемой территории составляет 89652,3 км². Исходными данными для картографических построений послужили: цифровая модель рельефа (ЦМР) - снимки SRTM (Shuttle Radar Topography Mission), загруженные с сайта USGS Earthexplorer, и производные из нее карты: уклонов, кривизны поверхности и экспозиции склонов, построенные с помощью «ArcGIS Desktop»; геологические карты листов М-46, N-46, загруженных с сайта ВСЕГЕИ им. А.П. Карпинского [23, 24]. 


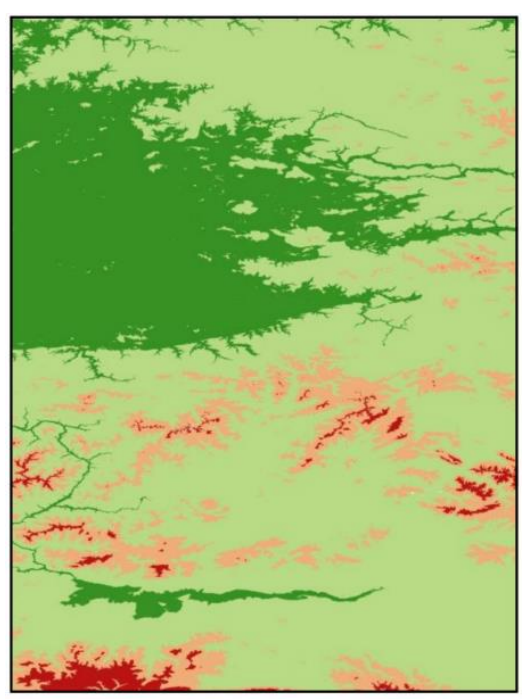

Абсолютные отметки, м

$\square_{600-1500}^{1500-2000}=0$

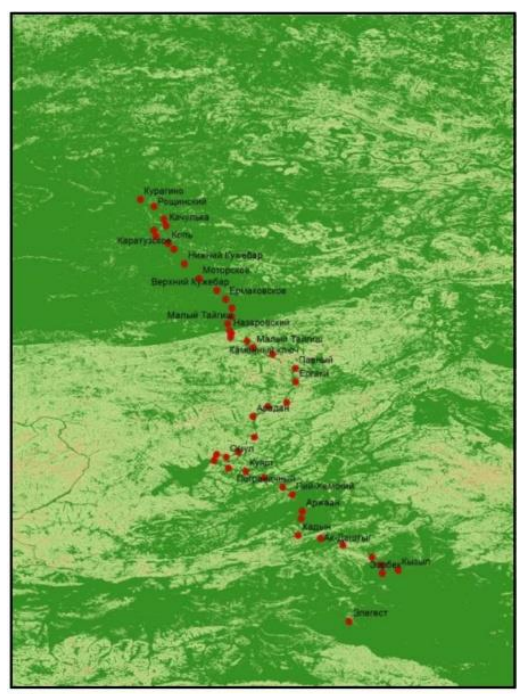

Уклоны, градус

$\square_{10-30}^{30-45}$

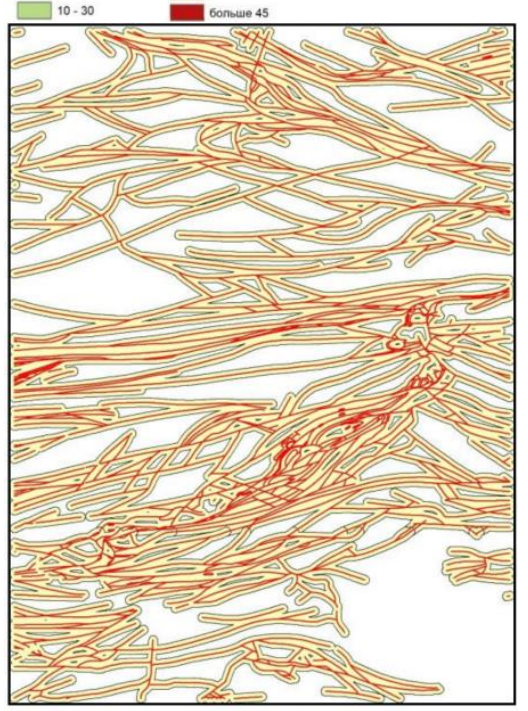

- Разломы

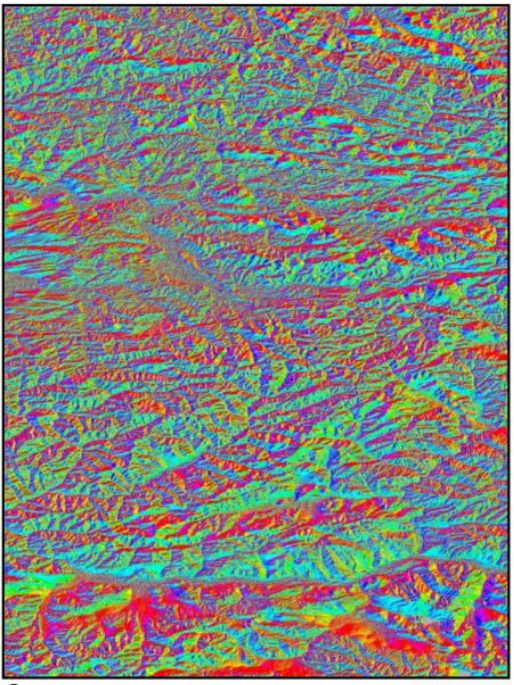

Экспозиция склонов, градус

$\square$ nocococrb (-1)

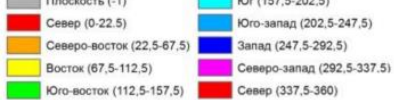

Cosep (337,5-360)

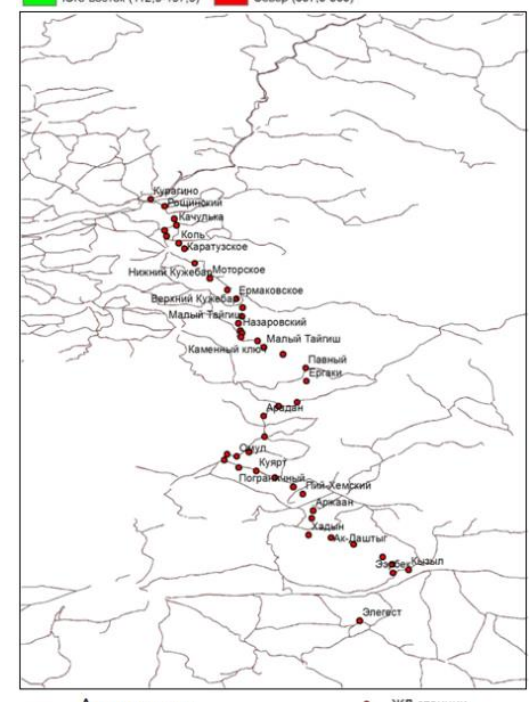

Автодороги

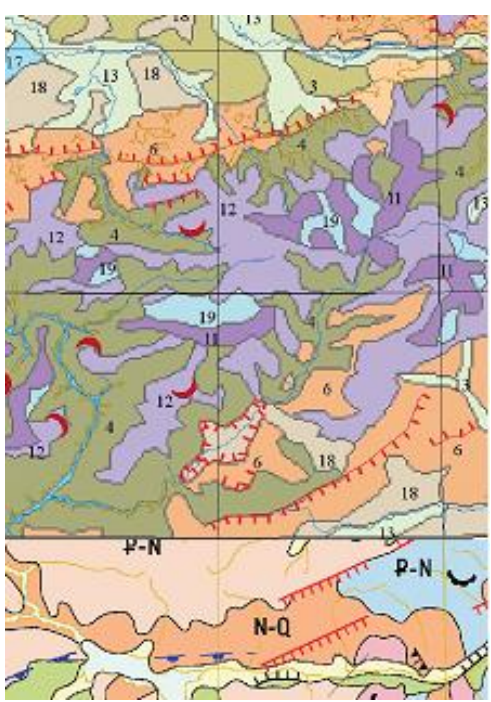

Геоморфологические карты N46, M46

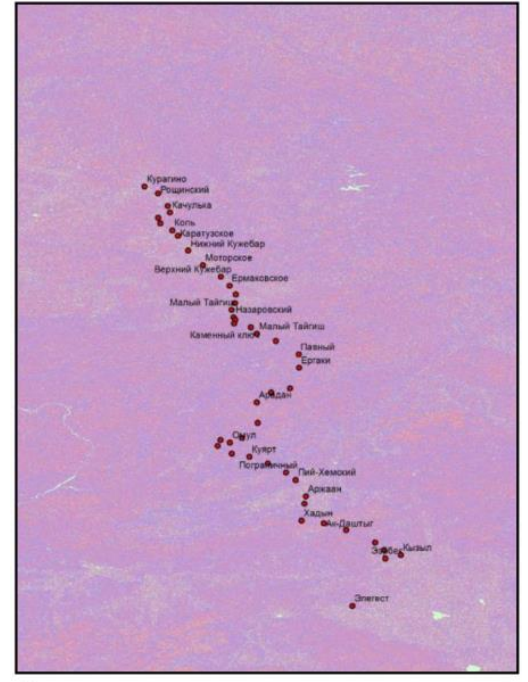

Кривизна склонов
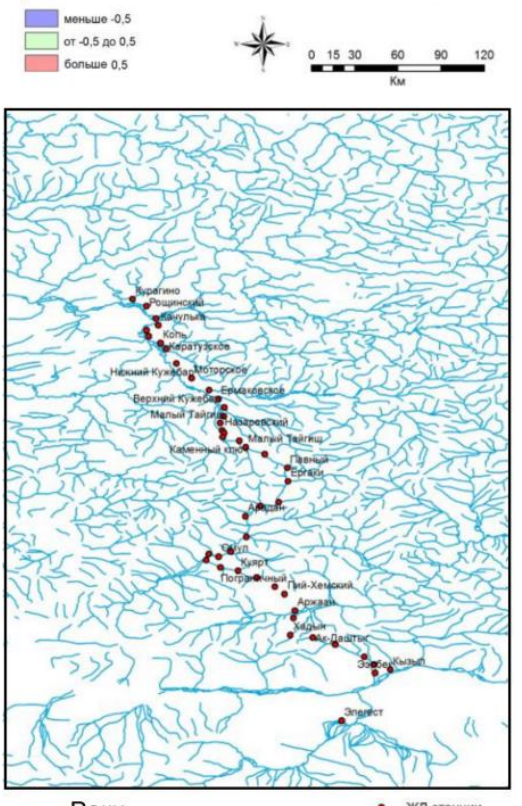

— Реки

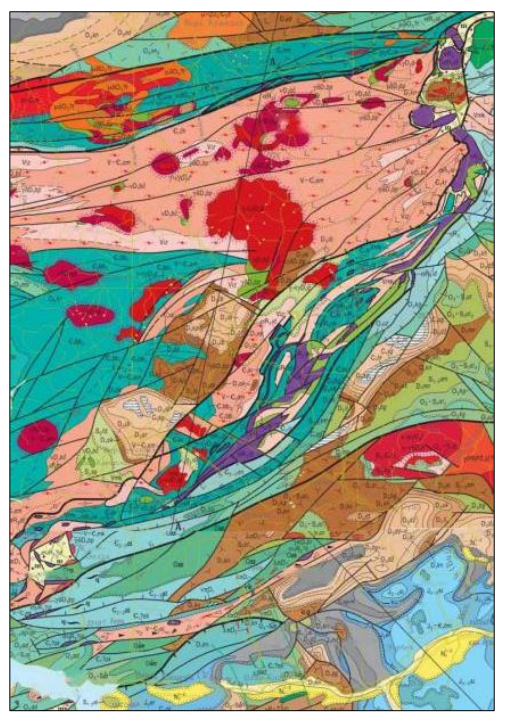

Геологические карты N46, M46

Рисунок. Исходные слои для оценки склоновых прочессов

Figure. Data layers for the assessment of slope processes 
Участки, подверженные развитию склоновых процессов, установлены по единым цифровым моделям комплектов листов М-46, N-46, и их общая площадь составляет 30833,8 км², или 40,1 \% от общей площади.

В качестве причинных факторов в данной работе рассмотрены следующие группы факторов: 1) геоморфологические: углы уклонов, экспозиция и кривизна склонов, высотные отметки, геоморфологические зоны; 2) геологические: генетические типы и литологический состав грунтов; 3) тектонические: расстояние от тектонических разломов; 4) гидрологические: расстояние от рек; 5) техногенное освоение территории: расстояние от дорог.

Угол уклона является основным параметром, влияющим на устойчивость склона. С повышением уклона напряжение сдвига в грунте увеличивается. Следовательно, возникает большая вероятность развития склоновых процессов. В данной работе значения угла уклона разделены на 4 класса: более $45^{\circ}$ (откосы), 45-30 (крутые склоны), 30-10 (умеренно крутые склоны), менее $10^{\circ}$ (пологие склоны).

Экспозищия склонов определяет воздействие солнечной энергии на влажностный режим, тип растительности склона, деятельность ветров и другие.

Кривизна поверхности относится к причинным факторам в связи с тем, что влияет на состояние увлажненности почвенного покрова. Почвенный покров вогнутого склона содержит большее количество воды и удерживает ее дольше, чем почвенный покров выпуклого склона. Также на выпуклых склонах чаще встречаются выходы скальных грунтов. Положительные значения кривизны указывают на то, что поверхность является выпуклой, отрицательные значения на вогнутую поверхность. Нулевое значение указывает, что поверхность плоская. Чем отрицательнее значение, тем выше вероятность возникновения оползней.

Bblcomные отметки оказывают влияние на устойчивость склона. Влияние высотных отметок проявляется через взаимосвязь с другими факторами. Район исследований разделен на 4 класса с высотами: до 600, $600-1500,1500-2000$ и более 2000 м.

Основные геоморфологические зоны. В различных геоморфологических условиях развиваются различные процессы. В данной работе выделены три основные геоморфологические зоны: 1) дезинтеграции с локальным ближним переносом и аккумуляцией - супеси с щебнем и дресвой; 2) склонового транзита и экзарационно-нивальной деструкции, в т. ч. осыпания, десерпции, обрушения, солифлюкции, речной эрозии, абразии - глыбы, отломы, щебни, дресва, супеси, суглинки; 3) площадной и линейной аккумулящии, в т. ч. озерной, озерно-аллювиальной, аллювиальной и делювиальной, пролювиальной, ледниковой и водноледниковой - пески, алевриты, глины, галечники, илы, суглинки с дресвой, щебнем.

Генетические типы и литология грунтов являются наиболее важным фактором при оценке возникновения склоновых процессов в связи с различной реакцией грунтов к нагрузкам, влажностному режиму и другим воздействиям. В данной работе анализирова- лись данные существующих геологических карт масштаба 1:1000000. Все образования разгруппированы на шесть классов: 1) интрузивные образования - диориты, плагиограниты, граниты, гранодиориты, габбро, анортозиты, габбро-анортозиты, габбронориты, дуниты, троктолиты; 2) метаморфические породы - аподуниты, апоперидотиты, апопироксениты, апогарцбургиты, аполерцолиты; 3) терригенновулканогенные - туффиты, туфопелиты, туфопесчаники, туфоалевролиты; 4) офиолитовые образования - андезиты, базальты, андезибазальты, трахиандезиты, трахиандезибазальты, риолиты, риодациты, трахириолиты, трахириодациты, дациты, игнимбриты, лейкограниты, гранодиориты, диориты, пегматиты; 5) осадочные образования - суглинки, пески, супеси, глины, галечники, известняки, алевролиты, конгломераты; 6) обломочные - туффы, гравелиты.

Расстояния от разломов. В зонах разломов часто наблюдаются крутые склоны, зоны сдвига ослабленных и трещиноватых пород. Для анализа вероятности развития склоновых процессов были выделены два класса с расстоянием от разломов до 3 км и более 3 км. В первой зоне влияние разрывных нарушений на возникновение склоновых процессов наибольшее.

Расстояние от рек входит в число ведущих факторов при развитии склоновых процессов. Устойчивость склонов нарушается за счет насыщения грунтов водой. Также водотоки оказывают разрушающее воздействие на склоны, размывая или насыщая основания берегов водой. В данной работе выделены шесть классов с расстояниями: до 50, 50-100, 100-150, 150-200, 200-250 и более 250 м.

Расстояние от дорог. Дороги являются результатом инженерной деятельности человека. При строительстве дорог нарушается устойчивость склонов, растительный покров, влажностный режим грунтов. Фактор «расстояние от дорог» разбит на шесть классов: до 50, 50-100, 100-150, 150-200, 200-250 и более 250 м. Данное ранжирование принято по публикациям [41-43].

Для определения «веса» каждого фактора использовалось два вышеописанных метода (FR и AHP). Beса классов каждого фактора приведены в таблице.

\section{Обсуждение результатов исследования}

Для определения взаимосвязи природных и антропогенных факторов со склоновыми процессами было проанализировано 9 факторов с 43 классами внутри них.

По методу соотношения частотностей (FR) наиболее тесные связи установлены между местопроявленими склоновых процессов и классами следующих факторов (в порядке убывания): уклоны поверхности более $45^{\circ}, 45 \ldots 30^{\circ}, 10 \ldots 30^{\circ}$; склоны северной экспозиции; поверхности с абсолютными отметками более 2000 м; геоморфологическая зона транзита; в геологическом отношении представленные метаморфическими породами и обломочными образованиями, с расстоянием до разломов менее 3 км. Вес вышеперечисленных факторов уменышается от 2,12 до 1,11 (таблица). Статистический анализ пространственного расположения проявлений склоновых процессов до- 
казывает, что другие параметры, такие как кривизна склонов (веса 0,98 и 1,03), склоны несеверной экспозиции (веса 0,86..0,91), расстояние до рек (веса $0,85 \ldots 0,86)$, расстояние до дорог (веса 0,57), также имеют значимую, но менее тесную связь с оползнями.
Минимальное проявление склоновых процессов наблюдается на территориях с уклонами менее $10^{\circ}$, с абсолютными отметками менее 600 м, представленными терригенно-вулканогенными образованиями, в геоморфологических зонах дезинтеграции и аккумуляции.

Таблица. Факторы развития склоновых процессов и их веса

Table. Slope processes causal factors and their weights

\begin{tabular}{|c|c|c|c|}
\hline $\begin{array}{c}\text { Слои данных } \\
\text { Data layers }\end{array}$ & $\begin{array}{l}\text { Классы } \\
\text { Classes }\end{array}$ & $\begin{array}{l}\text { Bec по AHP } \\
\text { AHP-weights }\end{array}$ & $\begin{array}{c}\text { Bec по FR } \\
\text { FR-weights }\end{array}$ \\
\hline \multirow{4}{*}{$\begin{array}{c}\text { Угол уклона, градус } \\
\text { Slope angle, degree }\end{array}$} & $>45$ & 0,54 & 2,12 \\
\hline & $45-30$ & 0,23 & 1,75 \\
\hline & $30-10$ & 0,14 & 1,46 \\
\hline & $<10$ & 0,08 & 0,73 \\
\hline \multirow{3}{*}{$\begin{array}{l}\text { Кривизна поверхности } \\
\text { Curvature }\end{array}$} & <-0,05 (вогнутые/concave) & 0,10 & 0,98 \\
\hline & от $-0,05$ до 0,05 (плоские/flat) & 0,26 & 0,43 \\
\hline & >0,05 (выпуклые/convex) & 0,64 & 1,03 \\
\hline \multirow{9}{*}{$\begin{array}{c}\text { Экспозиция склонов, градус } \\
\text { Slope aspect, degree }\end{array}$} & $<0$ & 0,01 & 0,61 \\
\hline & $\mathrm{C}(0-22,5 ; 337,5-360)$ & 0,45 & 1,46 \\
\hline & $\mathrm{CB}(22,5-67,5)$ & 0,17 & 0,87 \\
\hline & $\mathrm{B}(67,5-112,5)$ & 0,12 & 0,90 \\
\hline & ЮB $(112,5-157,5)$ & 0,08 & 0,89 \\
\hline & Ю $(157,5-202,2)$ & 0,06 & 0,86 \\
\hline & Ю3 $(202,5-247,5)$ & 0,05 & 0,88 \\
\hline & $3(247,5-292,5)$ & 0,03 & 0,90 \\
\hline & C3 $(292,5-337,5)$ & 0,03 & 0,91 \\
\hline \multirow{4}{*}{$\begin{array}{l}\text { Высотные отметки, м } \\
\text { Elevation, m }\end{array}$} & $<600$ & 0,06 & 0,43 \\
\hline & $600-1500$ & 0,10 & 1,16 \\
\hline & $1500-2000$ & 0,27 & 1,25 \\
\hline & $>2000$ & 0,57 & 1,43 \\
\hline \multirow{2}{*}{$\begin{array}{l}\text { Расстояние от разломов, км } \\
\text { Distance from faults, } \mathrm{km}\end{array}$} & $>3$ & 0,68 & 0,82 \\
\hline & $\leq 3$ & 0,32 & 1,11 \\
\hline \multirow{6}{*}{$\begin{array}{l}\text { Расстояние от дорог, м } \\
\text { Distance from roads, } m\end{array}$} & $0-50$ & 0,37 & 0,57 \\
\hline & $50-100$ & 0,27 & 0,57 \\
\hline & $100-150$ & 0,18 & 0,57 \\
\hline & $150-200$ & 0,10 & 0,57 \\
\hline & $200-250$ & 0,05 & 0,57 \\
\hline & $>250$ & 0,03 & 1,01 \\
\hline \multirow{6}{*}{$\begin{array}{l}\text { Расстояние от рек, } \mathrm{m} \\
\text { Distance from rivers, } \mathrm{m}\end{array}$} & $0-50$ & 0,37 & 0,85 \\
\hline & $50-100$ & 0,27 & 0,85 \\
\hline & $100-150$ & 0,18 & 0,85 \\
\hline & $150-200$ & 0,10 & 0,86 \\
\hline & $200-250$ & 0,05 & 0,87 \\
\hline & $>250$ & 0,03 & 1,01 \\
\hline \multirow{3}{*}{$\begin{array}{c}\text { Геоморфологические зоны } \\
\text { Geomorphology }\end{array}$} & Зона дезинтеграции/Disintegration zone & 0,73 & 0,00 \\
\hline & Зона транзита/Transit area & 0,17 & 1,37 \\
\hline & Зона аккумуляции/Accumulation zone & 0,10 & 0,00 \\
\hline \multirow{6}{*}{$\begin{array}{c}\text { Генетические типы, литология } \\
\text { Genetic types, lithology }\end{array}$} & Интрузивные образования/Intrusive rocks & 0,38 & 0,95 \\
\hline & Метаморфические породы /Metamorphic rocks & 0,26 & 1,33 \\
\hline & Терригенно-вулканогенные/Terrigenous-volcanogenic rocks & 0,16 & 0,41 \\
\hline & Офиолитовые образования/Ophiolites & 0,10 & 0,93 \\
\hline & Осадочные образования/Sedimentary rocks & 0,07 & 0,88 \\
\hline & Обломочные образования /Detrital formations & 0,05 & 1,20 \\
\hline
\end{tabular}

По методу анализа иерархий (АНР) наибольшие веса имеют такие классы: территории с абсоютными отметками более 2000 м, углами наклона более $45^{\circ}$, склоны северной экспозиции (веса изменяются соответственно от 0,57 до 0,45). Меньший вес имеют такие классы, как «интрузивные образования», «расстояние до дорог менее 50 м» и «расстояние до рек менее 50 м» с весами 0,38 и 0,37 (таблица). Минимальные веса $(0,03 \ldots 0,06)$ имеют склоны южной и западной экспозиции и участки с расстояниями до рек и дорог более $250 \mathrm{M}$.

\section{Выводы}

1. Рассмотрение основных природных компонентов территории трассы: сейсмотектоники, литологии, топографии, гидрологии, гидрогеологии и мерзлоты, показало, что в целом инженерногеологические условия трассы являются достаточно сложными в связи с широким распространением геологических процессов.

2. В настоящем исследовании были применены статистический анализ и ГИС для определения связи природных и антропогенных параметров с активностью склоновых процессов в районе проектируемой железной дороги и их ранжирование. Значимость факторов оценена двумя методами: методом анализа иерархий и методом соотношения частотностей. Последний метод позволил оценить площадную пораженность территории склоновы- 
ми процессами. Основными природными факторами, контролирующими активность склоновых процессов, являются: уклоны поверхности, абсолютные отметки поверхности, геологические факторы. Что касается антропогенных факторов, то статистический анализ показал, что имеется тесная связь гравитационных смещений склонов и дорог. Их частота и масштабы увеличиваются в непосредственной близости к дорогам.

3. Предлагаемая методология раскрывает относительно доступный и быстрый способ определения взаимосвязи природных и антропогенных параметров с активностью склоновых процессов в горной местности. В настоящее время топографические, геологические, гидрологические данные общедоступны, анализ данных средствами ГИС обладает высокой точностью. В региональных ис-

\section{СПИСОК ЛИТЕРАТУРЫ}

1. Andriamamonjisoa S.N., Hubert-Ferrari A. Combining geology, geomorphology and geotechnical data for a safer urban extension: application to the Antananarivo capital city (Madagascar) // Journal of African Earth Sciences. - 2019. - V. 151. - P. 417-437.

2. Baynes F.J., Fookes P.G., Kennedy J.F. The total engineering geology approach applied to railways in the Pilbara, Western Australia // Bulletin of Engineering Geology and the Environment. - 2005. - V. 64. - № 1. - P. 67-94.

3. The interplay of structural pathway and weathering intensity in forming mass-wasting processes in deeply weathered gneissic rocks (Sila Massif, Calabria, Italy) / D. Biondino, L. Borrelli, S. Critelli, F. Muto, G. Gullà // Journal of Maps. - 2018. V. 14. - № 2. - P. 242-256

4. Cheskidov V.V., Manevich A.I. Engineering and geological support for slope stability monitoring as a part of transport infrastructure construction projects // Mining science and technology. - 2016. - № 1. - P. 50-57.

5. Failache M.F., Zuquette L.V. Geological and geotechnical land zoning for potential Hortonian overland flow in a basin in southern Brazil // Engineering Geology. - 2018. - V. 246. - P. 107-122.

6. Engineering geological mapping of earthquake-induced landslides in South Lefkada Island, Greece: evaluation of the type and characteristics of the slope failures / N. Grendas, V. Marinos, G. Papathanassiou, A. Ganas, S. Valkaniotis // Environmental Earth Sciences. - 2018. - V. 77. - № 12. - P. 425. URL https://doi.org/10.1007/s12665-018-7598-9 (дата обращения 16.06.2021).

7. Hassanpour J., Firouzei Y., Hajipour G. A regional-scale engineering geological study for selecting suitable rock masses for constructing unlined oil storage caverns in Southern Zagros, Iran // Bulletin of Engineering Geology and the Environment. - 2019. V. 78. - № 1. - P. 267-280.

8. Hearn G.J. Geomorphology in engineering geological mapping and modelling // Bulletin of Engineering Geology and the Environment. - 2019. - V. 78. - № 2. - P. 723-742.

9. Landslide mapping from aerial photographs using change detection-based Markov random field / Z. Li, W. Shi, P. Lu, Q. Wang, Z. Miao // Journal Remote Sensing of Environment. 2016. - V. 187. - P. 76-90.

10. Martínez-Graña A.M., Goy J.L., Zazo C. Engineering geology maps for planning and manegement of natural parks: «Las Batuecas-Sierra de Francia» and «Quilamas» (Central Spanish System, Salamanca, Spain) // Geosciences. - 2013. - V. 1. - P. 46-62.

11. The value of data - the Qatar geologic mapping project / C.L. Meehan, S. Kumar, M.A. Pando, A.G. Mouradian, A.F. Saleh // Geotechnical Special Publication. - 2019. - V. 3. № 14. - P. 12-23.

12. Development of a 3D structural model of a mine by consolidating different data sources / M. Morales, K.K. Panthi, K. Botsialas, K.H. Holmøy // Bulletin of Engineering Geology and the Environment. - 2019. - V. 78. - № 1. - P. 35-53. следованиях применяемая процедура может быть использована для локализации участков, подверженных склоновым процессам, для составления карт восприимчивости территории к их развитию и разработке мероприятий для снижения опасности от них для населения и окружащей среды.

4. При проектировании трассы следует учесть опыт строительства линии Абакан-Тайшет, а также китайских специалистов по подготовке и осуществлению строительства Цинхай-Тибетской железной дороги, самой высокогорной в мире, проходящей по территории с многолетнемерзлыми грунтами.

Исследование выполнено в Томском политехническом университете в рамках программы повымения конкурентоспособности Томского политехнического университета (средства ВИУ).

13. Privett K.D. The lines of evidence approach to challenges faced in engineering geological practice // Quarterly Journal of Engineering Geology and Hydrogeology. - 2019. - V. 52. - № 2. - P. 141-172.

14. Ullah K.M., Mansourian A. Evaluation of land suitability for urban land-use planning: case study Dhaka city // Transactions in GIS. - 2016. - V. 20. - № 1. - P. 20-37.

15. Hazards posed by active major faults along the Golmud-Lhasa railway route, Tibetan Plateau, China / Z. Wu, P.J. Barosh, D. Hu, P. Ye, W. Jiang // Engineering Geology. - 2004. - V. 74. № 3-4. - P. 163-182.

16. Yang J. Research on the new railway field geological survey system based on mobile GIS // Journal of Railway Engineering Society. - 2019. - V. 36. - № 2. - P. 15-20.

17. Youssef A.M. Landslide susceptibility delineation in the Ar-Rayth area, Jizan, Kingdom of Saudi Arabia, using analytical hierarchy process, frequency ratio, and logistic regression models // Environmental Earth Sciences. - 2015. - V. 73. - № 12. P. $8499-8518$

18. Zuquette L.V., Failache M. Mapping groundwater pollution vulnerability with application in a basin in southern Brazil // Environmental Earth Sciences. - 2018. - V. 77. - № 19. - P. 689. URL: https://doi.org/10.1007/s12665-018-7862-z (дата обращения 16.06.2021).

19. Ломтадзе В.Д. Словарь по инженерной геологии. - СПб: СПбГИ, 1999. -360 с

20. Трофимов В.Т., Красилова Н.С. Инженерно-геологические карты. - М.: КДУ, Добросвет, 2018. - 383 с.

21. Инженерная геология России. Том 3. Инженерно-геологические структуры России / В.Т. Трофимов, Т.И. Аверкина, Т.В. Андреева, С.Д. Балыкова, А.В. Бершов, Ю.К. Васильчук, Е.О. Головина, А.В. Ершова, Н.С. Красилова, М.Б. Куринов, В.М. Ладыгин, Ю.В. Фролова. - М.: КДУ, 2015. - 710 с.

22. Трофимов В.Т. Зональность инженерно-геологических условий континентов Земли. - М.: Изд-во МГУ, 2002. - 348 с.

23. Государственная геологическая карта Российской Федерации. Масштаб 1:1000000 (третье поколение) / под ред. Б.А. Блюман. Серия Алтае-Саянская. Лист М-46 - Кызыл. Объяснительная записка. - СПб.: Картографическая фабрика ВСЕГЕИ, 2008. $349 \mathrm{c}$.

24. Государственная геологическая карта Российской Федерации. Масштаб 1:1000000 (третье поколение) / под ред. Е.П. Миронюк. Серия Алтае-Саянская. Лист N-46 - Абакан. Объяснительная записка. - СПб.: Картографическая фабрика ВСЕГЕИ, 2008. $-391 \mathrm{c}$.

25. Особенности проявления неблагоприятных природных процессов на территории республики Тыва / А.Д. Абалаков, А.И. Шеховцов, Г.И. Лысанова, Л.С. Новикова // Успехи современного естествознания. - 2016. - № 6. - С. 132-137. URL: http://www.natural-sciences.ru/ru/article/view?id=35980 (дата обращения: 11.05.2021).

26. СП 14.13330.2018. Строительство в сейсмических районах. Актуализированная редакция СНиП II-7-81*. - М.: ФГУП Стандартинформ, 2018. - 122 c. 
27. СП 115.13330.2016. Геофизика опасных природных воздействий. - М.: ФГУП Стандартинформ, 2016. - 49 с.

28. Яббарова Е.Н., Латыпов А.И Уточнение корреляционных зависимостей между данными статического зондирования и деформационно-прочностными характеристиками грунтов // Известия Томского политехнического университета. Инжиниринг георесурсов. - 2021. - Т. 332. - № 6. - С. 82-89.

29. Строкова Л.А., Надеждина Ю.Ю. Типизация инженерногеологических условий территории трассы проектируемой железной дороги Элегест-Кызыл-Курагино // Известия Томского политехнического университета. Инжиниринг георесурсов. -2020 . - T. 331. - № 2. - С. 64-77.

30. Строкова Л.А., Епифанова Е.А., Коржнева Т.Г. Численный анализ поведения основания опоры моста на старой железнодорожной линии // Известия Томского политехнического университета. Инжиниринг георесурсов. - 2017. - Т. 328. - № 5. C. $125-139$.

31. Епифанова Е.А., Строкова Л.А. Оценка деформаций исторического здания в Томске с помощью комплексного подхода, основанного на сочетании наземного лазерного сканирования и конечно-элементного моделирования // Известия Томского политехнического университета. Инжиниринг георесурсов. 2018. - T. 329. - № 5. - C. 27-41.

32. Епифанова Е.А., Строкова Л.А. Анализ деформаций прожекторной мачты при помощи наземного лазерного сканирования и метода конечных элементов // Известия Томского политехнического университета. Инжиниринг георесурсов. 2019. - T. 330. - № 5. - C. 7-17.

33. Опыт инженерно-геологического районирования по несущей способности грунтов промплощадки Эльгинского ГОК в Якутии / Л.А. Строкова, С.А. Дмитриева, Н.В. Осьмушкина, А.В. Осьмушкин // Известия Томского политехнического университета. Инжиниринг георесурсов. - 2019. - Т. 330. - № 2. C. $175-185$

34. Strokova L. Recognition of geological processes in permafros conditions // Bulletin of Engineering Geology and the Environment. - 2019. - V. 78. - № 8. - P. 5517-5530.

35. Фи Хонг Тхинь, Строкова Л.А. Типизация грунтовых толщ территории города Ханой (Вьетнам) при изучении оседания земной поверхности из-за извлечения подземных вод // Известия Томского политехнического университета. Инжиниринг георесурсов. - 2017. - Т. 328. - № 4. - С. 6-17.

36. Строкова Л.А., Галеева Э.И., Леонова А.В. Районирование инженерно-геокриологических условий трассы трубопровода на Восточно-Мессояхском нефтегазоконденсатном месторождении // Известия Томского политехнического университета Инжиниринг георесурсов. - 2020. - Т. 331. - № 10. - С. 14-22.

37. Строкова Л.А., Ежкова А.В., Леонова А.В. Применение линеаментного анализа для оценки карстоопасности при проектировании магистрального газопровода в южной Якутии // Известия Томского политехнического университета. Инжиниринг георесурсов. - 2020. - Т. 331. - № 11. - С. 117-126.

38. Оценка инженерно-геокриологических условий Берегового нефтегазоконденсатного месторождения / Л.А. Строкова, Д.В. Пургина, Э.И. Галеева, А.Н. Курчатова // Известия Томского политехнического университета. Инжиниринг георесурсов. - 2018. - T. 329. - № 12. - С. 6-19.

39. Strokova L. A. Numerical model of surface subsidence during subway tunneling. Soil Mechanics and Foundation Engineering. 2009. - V. 46 - № 3 - P. 117-119.

40. Karst hazard assessment in the design of the main gas pipeline (South Yakutia) / L.A. Strokova, E.M. Dutova, A.V. Ermolaeva I.N. Alimova, A.B. Strelnikova // IOP Conference Series: Earth and Environmental Science - 2015. - V. 27. - 012032. URL http://iopscience.iop.org/article/10.1088/1755-1315/27/1/012032 (дата обращения 10.06.2021)

41. Ghorbanzadeh O., Feizizadeh B., Blaschke T. An interval matrix method used to optimize the decision matrix in AHP technique for land subsidence susceptibility mapping // Environmental Earth Sciences. - 2018. - V. 77. - Article number 584 URL: https://doi.org/10.1007/s12665-018-7758-y (дата обращения 16.06.2021).

42. Landslide susceptibility mapping for Austria using geons and optimization with the dempster-shafer theory / T. Gudiyangada Nachappa, S. Tavakkoli Piralilou, O. Ghorbanzadeh, H. Shahabi,
T. Blaschke // Applied Sciences. - 2019. - V. 9. - № 24. Article number 5393. URL: https://doi.org/10.3390/app9245393 (дата обращения 16.06.2021).

43. Comparison and validation of per-pixel and object-based approaches for landslide susceptibility mapping / T. Gudiyangada Nachappa, S. Kienberger, S.R. Meena, D. Hölbling, T. Blaschke // Geomatics, Natural Hazards and Risk. - 2020. - V. 11. - № 1. P. 572-600. URL: https://doi.org/10.1080/19475705.2020.1736190 (дата обращения 16.06.2021).

44. Estimating the quality of landslide susceptibility models / F. Guzzetti, P. Reichenbach, F. Ardizzone, M. Cardinali, M. Galli // Geomorphology. - 2006. - V. 81. - P. 166-184. DOI: 10.1016/j.geomorph.2006.04.007

45. Ivanova E. Landslide susceptibility mapping using Frequency Ratio and Analytic Hierarchy Process (AHP): comparative study of two areas in Bulgaria // Proceedings of the International Conference Analysis and Management of Changing Risk for Natural Hazards. - Padua, Italy, 18-19 November, 2014. pp. AP23-1-AP23-9. URL: https://www.researchgate.net/publication/ 318589814 (дата обращения 16.06.2021).

46. Rasyid A.R., Bhandary N.P., Yatabe R. Performance of frequency ratio and logistic regression model in creating GIS based landslides susceptibility map at Lompobattang Mountain, Indonesia // Geoenvironmental Disasters. - 2016. - V.3. Article number 19. URL: https://doi.org/10.1186/s40677-0160053-х (дата обращения 16.06.2021).

47. Zhang Y.X., Lan H.X., Li L.P. Optimizing the frequency ratio method for landslide susceptibility assessment: a case study of the Caiyuan Basin in the southeast mountainous area of China // Journal of Mountain Science. - 2020 - V. 17. - Article number 2. URL: https://doi.org/10.1007/s11629-019-5702-6 (дата обращения 16.06.2021)

48. Zhuang J., Peng J., Zhu X. Spatial distribution and susceptibility zoning of geohazards along the Silk Road, Xian-Lanzhou // Environmental Earth Sciences. - 2016. - V. 75. - Article number 711. URL: https://doi.org/10.1007/s12665-016-5428-5 (дата обращения 16.06.2021).

49. Lee S., Thalib J.A. Probabilistic landslide susceptibility and factor effect analysis // Environmental Geology. - 2005. - V. 47. P. 982-990. URL: https://doi.org/10.1007/s00254-005-1228-z (дата обращения 16.06.2021).

50. Саати Т.Л. Принятие решений. Метод анализа иерархий. - М.: Радио и связь, 1989. -316 с

51. Linden A. Measuring diagnostic and predictive accuracy in disease management: An introduction to receiver operating characteristic (ROC) analysis // Journal of Evaluation in Clinical Practice. 2006. - V. 12. - P. 132-139. DOI: 10.1111/j.1365-2753.2005. 00598.x

52. Assessment of freeze-thaw hazards and water features along the China-Russia crude oil pipeline in permafrost regions / M. Chai, G. Li, W. Ma, Y. Cao, G. Wu, Y. Mu, Q. Du // Remote Sensing. 2020. - V. 12. - № 21. - C. 35-76.

53. Automatic detection of burial mounds (kurgans) in the Altai Mountains / F. Chen, R. Zhou, T. van de Voorde, X. Chen, J. Bourgeois, W. Gheyle, R. Goossens, J. Yang, W. Xu // Journal of Photogrammetry and Remote Sensing. - 2021. - V. 177. P. 217-237.

54. Coseismic surface ruptures of the 2003 Chuya Earthquake (Gorny Altai): slip geometry and spatial patterns / E.M. Vysotsky, I.S. Novikov, O.V. Lunina, A.R. Agatova, R.K. Nepop // Russian Geology and Geophysics. - 2021. - V. 62. - № 3. - P. 278-290. DOI: https://doi.org/10.2113/RGG20194133

55. Franklin S.E. Interpretation and use of geomorphometry in remote sensing: a guide and review of integrated applications // International Journal of Remote Sensing. - 2020. - V. 41. - № 19. P. 7700-7733.

56. Groundwater dynamics within a watershed in the discontinuous permafrost zone near Umiujaq (Nunavik, Canada) / J.M. Lemieux, R. Fortier, R. Murray, S. Dagenais, M. Cochand, H. Delottier, M. Parhizkar // Hydrogeology Journal. - 2020. - V. 1. - P. 1-19.

57. Massive ice control on permafrost coast erosion and sensitivity M. Lim, D. Whalen, J. Martin, P.J. Mann, S. Hayes, P. Fraser // Geophysical Research Letters. - 2020. - V. 47. - e2020GL087917. URL: https://doi.org/10.1029/2020GL087917 (дата обращения 16.06.2021). 
58. Mapping thermokarst lakes and ponds across permafrost landscapes in the Headwater Area of Yellow River on northeastern Qinghai-Tibet Plateau / R.-D. Șerban, H. Jin, M. Șerban, D. Luo, Q. Wang, X. Jin, Q. Ma // International Journal of Remote Sensing. - 2020. - V. 41. - № 18. - P. 7042-7067. DOI: $10.1080 / 01431161.2020 .1752954$

59. Engineering risk analysis in cold regions: state of the art and perspectives / W. Yu, T. Zhang, Y. Lu, F. Han, Y. Zhou, D. Hu //
Cold Regions Science and Technology. - 2020. - V. 171. 102963.

60. A new approach to mapping permafrost and change incorporating uncertainties in ground condition and climate projections / Y. Zhang, I. Olthof, R.H. Fraser, S.A. Wolfe // The Cryosphere. 2014. - V. 8. - № 6. - P. 2177-2194. URL: https://doi.org/ 10.5194/tcd-8-1895-2014 (дата обращения 16.06.2021).

Поступила 08.07.2021 2.

\section{Информация об авторах}

Строкова Л.А., доктор геолого-минералогических наук, профессор отделения геологии Инженерной школы природных ресурсов Национального исследовательского Томского политехнического университета.

Надеждина Ю.Ю., аспирант отделения геологии Инженерной школы природных ресурсов Национального исследовательского Томского политехнического университета. 
UDC 624.131

\title{
NATURAL AND ANTHROPOGENIC FACTORS RELATED TO ACTIVITY OF SLOPE PROCESSES ON THE TERRITORY OF THE PROJECTED RAILWAY ELEGEST-KYZYL-KURAGINO
}

\author{
Lyudmila A. Strokova ${ }^{1}$, \\ sla@tpu.ru
}

\author{
Yulia Y. Nadezhdina 1 , \\ levak.yuliya@mail.ru \\ 1 National Research Tomsk Polytechnic University, \\ 30, Lenin avenue, Tomsk, 634050, Russia.
}

\begin{abstract}
The study is relevant due to the development of the project of the first railway in Tyva, which should link Tyva with the Krasnoyarsk territory. The route is planned in very difficult engineering-geological conditions. The article presents an assessment of the engineering and geological conditions of the route territory, which is necessary to support the decision-making process for the placement of structures.

This study aims to identify the influence of physical and anthropogenic factors in activity of slope processes on the territory such as landslides, mobile scree, avalanches, solifluction, stone glaciers, kurums, splashes, mudflows.

Object of the study is the geological environment of the area of the projected Kyzyl-Kuragino highway. We considered the main factors affecting the formation of slope processes such as lithology; topography; seismotectonic; geotechnic; hydrology-hydrogeology; permafrost and presence of roads. Each natural and anthropogenic factor is further divided into sub-categories.

Methods. We used statistical analysis of the frequency of slope processes and the method of hierarchy analysis along with a geographical information system to determine the relationship between natural and anthropogenic factors and the activity of slope processes.

The results. We analyzed 9 factors with 43 classes within them to determine the relationship of natural and anthropogenic factors with slope processes. We found that the most informative parameters are the slope of the surface, its elevation, slope aspect, genetic type and lithology of soils. The frequency of gravitational displacements increases on the northern slopes with a slope of more than $10^{\circ}$, with marks of more than $2000 \mathrm{~m}$, composed of metamorphic rocks and detrital formations. The frequency and scale of landslides are increasing in the immediate vicinity of roads. Their maximum values are observed within the 50-meter buffer zone. The results of determining the weights by two methods showed high convergence of the results.

Summary. The results provide information on natural and anthropogenic factors characterizing slope processes in the study area. The applied methodology rapidly estimates areas prone to slope processes and it may be utilized for landslide hazard assessment mapping as well as for preparation of planning documentation and recommendations for engineering protection of the territory.
\end{abstract}

\section{Key words:}

Soils, slope processes, geographic information system, frequency ratio, analytical hierarchical process.

The research was carried out at Tomsk Polytechnic University within the Competitiveness Enhancement Program of Tomsk Polytechnic University (VIU funds).

\section{REFERENCES}

1. Andriamamonjisoa S.N., Hubert-Ferrari A. Combining geology, geomorphology and geotechnical data for a safer urban extension application to the Antananarivo capital city (Madagascar). Journal of African Earth Sciences, 2019, vol. 151, pp. 417-437.

2. Baynes F.J., Fookes P.G., Kennedy J.F. The total engineering geology approach applied to railways in the Pilbara, Western Australia. Bulletin of Engineering Geology and the Environment, 2005, vol. 64, no. 1, pp. 67-94.

3. Biondino D., Borrelli L., Critelli S., Muto F., Gullà G. The interplay of structural pathway and weathering intensity in forming mass-wasting processes in deeply weathered gneissic rocks (Sila Massif, Calabria, Italy). Journal of Maps, 2018, vol. 14, no. 2, pp. 242-256.

4. Cheskidov V.V., Manevich A.I. Engineering and geological support for slope stability monitoring as a part of transport infrastructure construction projects. Mining science and technology, 2016, no. 1, pp. 50-57.

5. Failache M.F., Zuquette L.V. Geological and geotechnical land zoning for potential Hortonian overland flow in a basin in southern Brazil. Engineering Geology, 2018, vol. 246, pp. 107-122.

6. Grendas N., Marinos V., Papathanassiou G., Ganas A., Valkaniotis S Engineering geological mapping of earthquake-induced landslides in South Lefkada Island, Greece: evaluation of the type and characteristics of the slope failures. Environmental Earth Sciences, 2018, vol. 77, no. 12, p. 425. Available at: https://doi.org/ 10.1007/s12665-018-7598-9 (accessed 16 June 2021).
7. Hassanpour J., Firouzei Y., Hajipour G. A regional-scale engineering geological study for selecting suitable rock masses for constructing unlined oil storage caverns in Southern Zagros, Iran. Bulletin of Engineering Geology and the Environment, 2019, vol. 78 , no. 1, pp. 267-280.

8. Hearn G.J. Geomorphology in engineering geological mapping and modelling. Bulletin of Engineering Geology and the Environment, 2019, vol. 78, no. 2, pp. 723-742.

9. Li Z., Shi W., Lu P., Wang Q., Miao Z. Landslide mapping from aerial photographs using change detection-based Markov random field. Journal Remote Sensing of Environment, 2016, vol. 187, pp. 76-90.

10. Martínez-Graña A.M., Goy J.L., Zazo C. Engineering geology maps for planning and manegement of natural parks: «Las Batuecas-Sierra de Francia» and «Quilamas» (Central Spanish System, Salamanca, Spain). Geosciences, 2013, vol. 1, pp. 46-62.

11. Meehan C.L., Kumar S., Pando M.A., Mouradian A.G., Saleh A.F. The value of data The Qatar geologic mapping project. Geotechnical Special Publication, 2019, vol. 3, no. 14, pp. 12-23.

12. Morales M., Panthi K.K., Botsialas K., Holmøy K.H. Development of a 3D structural model of a mine by consolidating different data sources. Bulletin of Engineering Geology and the Environment, 2019, vol. 78, no. 1, pp. 35-53.

13. Privett K.D. The lines of evidence approach to challenges faced in engineering geological practice. Quarterly Journal of Engineering Geology and Hydrogeology, 2019, vol. 52, no. 2, pp. 141-172. 
14. Ullah K.M., Mansourian A. Evaluation of land suitability for urban land-use planning: Case study Dhaka city. Transactions in GIS, 2016, vol. 20, no. 1, pp. 20-37.

15. Wu Z., Barosh P.J., Hu D., Ye P., Jiang W. Hazards posed by active major faults along the Golmud-Lhasa railway route, Tibetan Plateau, China. Engineering Geology, 2004, vol. 74, no. 3-4, pp. $163-182$.

16. Yang J. Research on the new railway field geological survey system based on mobile GIS. Journal of Railway Engineering Society, 2019, vol. 36, no. 2, pp. 15-20.

17. Youssef A.M. Landslide susceptibility delineation in the Ar-Rayth area, Jizan, Kingdom of Saudi Arabia, using analytical hierarchy process, frequency ratio, and logistic regression models Environmental Earth Sciences, 2015, vol. 73, no. 12, pp. 84998518.

18. Zuquette L.V., Failache M. Mapping groundwater pollution vulnerability with application in a basin in southern Brazil. Environmental Earth Sciences, 2018, vol. 77, no. 19, p. 689. Available at: https://doi.org/10.1007/s12665-018-7862-z (accessed 16 June 2021)

19. Lomtadze V.D. Slovar po inzhenernoy geologii [Lexicon of engineering geology]. St-Petersburg, SPGI Publ., 1999. $360 \mathrm{p}$.

20. Trofimov V.T., Krasilova N.S. Inzhenerno-geologicheskie karty [Engineering-geological maps]. Moscow, KDU, Dobrosvet Publ., $2018.383 \mathrm{p}$.

21. Trofimov V.T., Averkina T.I., Andreeva T.V., Balykova S.D., Bershov A.V., Vasilchuk Yu.K., Golovina E.O., Ershova A.V., Krasilova N.S., Kurinov M.B., Ladygin V.M., Frolova Yu.V. Inzhenernaya geologiya Rossii. T. 3. Inzhenerno-geologicheskie struktury Rossii [Engineering geology of Russia. Vol. 3. Engineering-geological structures of Russia]. Moscow, KDU Publ. $2015.710 \mathrm{p}$

22. Trofimov V.T. Zonalnost inzhenerno-geologicheskikh usloviy kontinentov Zemli [Zoning of engineering-geological conditions of the earth's continents]. Moscow, Moscow state University Publ., 2002. $348 \mathrm{p}$.

23. Gosudarstvennaya geologicheskaya karta Rossiyskoy Federatsii. Masshtab 1:1000000 (trete pokolenie). Seriya Altai-Sayan. List M-46Kyzyl. [The state geological map of the Russian Federation. Scale 1:1000000 (third generation). Series Altai-Sayan Sheet M-46 Kyzyl. Explanatory note]. Ed. by B.A. Blyuman. St-Petersburg, Map factory VSEGEI Publ., 2008. 349 p.

24. Gosudarstvennaya geologicheskaya karta Rossiyskoy Federatsii. Masshtab 1:1000000 (trete pokolenie). Seriya Altai-Sayan List N-46 Abakan [The state geological map of the Russian Federation. Scale 1:1000000 (third generation). Series Altai-Sayan Sheet N-46 Abakan. Explanatory note]. Ed. by Mironyuk E.P. St-Petersburg, Map factory VSEGEI Publ., 2008. 391 p.

25. Abalakov A.D., Shekhovtsov A.I., Lysanova G.I., Novikova L.S Osobennosti projavlenija neblagoprijatnyh prirodnyh processov na territorii respubliki Tyva [Peculiarities of manifestation of hazardous natural processes on the territory of the Republic of Tuva]. Uspekhi sovremennogo estestvoznaniya, 2016, no. 6, pp. 132-137. Available at: http://www.naturalsciences.ru/ru/article/view?id= $35980($ accessed 11 May 2021)

26. SP 14.13330.2018. Stroitelstvo $v$ seysmicheskikh rayonakh. Aktualizirovannaya redaktsiya $\mathrm{SNiP}$ II-7-81* [Set of rules 14.13330.2018. Seismic building design code]. Moscow, StandardInform Publ., 2018. 122 p.

27. SP 115.13330.2016. Geofizika opasnykh prirodnykh vozdeystviy [Set of rules 115.13330.2016. Geophysics of natural hazards]. Moscow, StandardInform Publ., 2016. 49 p.

28. Yabbarova E.N., Latypov A.I. Clarification of correlation dependences between the parameters of cone penetration test and strength and deformation characteristics of soils. Bulletin of the Tomsk Polytechnic University. Geo Assets Engineering, 2021, vol. 332, no. 6, pp. 82-89. In Rus.

29. Strokova L.A. Nadezhdina Yu.Yu. Typification of engineering and geological conditions of the territory of the route of the projected railway Elegest-Kyzyl-Kuragino. Bulletin of the Tomsk Polytechnic University. Geo Assets Engineering, 2020, vol. 331, no 2, pp. 64-77. In Rus.

30. Strokova L.A., Epifanova E.A., Korzhneva T.G. Numerical analysis of bridge foundation behaviour on the old railway line.
Bulletin of the Tomsk Polytechnic University. Geo Assets Engineering, 2017, vol. 328, no. 5, pp. 125-139. In Rus.

31. Epifanova E.A., Strokova L.A. Evaluation of deformation of a historic building in Tomsk by an integrated approach based on terrestrial laser scanner and finite element modeling. Bulletin of the Tomsk Polytechnic University. Geo Assets Engineering, 2018, vol. 329, no. 5, pp. 27-41. In Rus.

32. Epifanova E.A., Strokova L.A. Numerical analysis of deformations of the lighting mast by ground laser scanning and finite elements method. Bulletin of the Tomsk Polytechnic University. Geo Assets Engineering, 2019, vol. 330, no. 5, pp. 7 17. In Rus.

33. Strokova L. Recognition of geological processes in permafrost conditions. Bulletin of Engineering Geology and the Environment, 2019, vol. 78, no. 8, pp. 5517-5530.

34. Strokova L.A., Dmitrieva S.A. Osmushkina N.V., Osmushkin A.V. Experience of engineering-geological zoning on bearing capacity of soils of the industrial site of Elga coal-preparation plant in Yakutia. Bulletin of the Tomsk Polytechnic University. Geo Assets Engineering, 2019, vol. 330, no. 2, pp. 175-185. In Rus.

35. Phi H.T., Strokova L.A. Classification of soil types for Hanoi (Vietnam) when studying land subsidence at groundwater extraction. Bulletin of the Tomsk Polytechnic University. Geo Assets Engineering, 2017, vol. 328, no. 4, pp. 6-17. In Rus.

36. Strokova L.A., Galeeva E.I., Leonova A.V. Zoning of engineeringgeocryological conditions of the pipelines on VostochnoMessoyakhskoe field oil and gas condensate field. Bulletin of the Tomsk Polytechnic University. Geo Assets Engineering, 2020, vol. 331, no. 10, pp. 14-22. In Rus.

37. Strokova L.A., Ezhkova A.V., Leonova A.V. The application of lineament analysis to assess the karst hazard in the design of the main gas pipeline in South Yakutia. Bulletin of the Tomsk Polytechnic University. Geo Assets Engineering, 2020, vol. 331, no. 11, pp. 117-126. In Rus.

38. Strokova L.A., Purgina D.V., Galeeva E.I., Kurchatova A.N Evaluation of engineering-geocryological conditions of the Beregovoye oil and gas condensate field. Bulletin of the Tomsk Polytechnic University. Geo Assets Engineering, 2018, vol. 329, no. 12, pp. 6-19. In Rus.

39. Strokova L. A. Numerical model of surface subsidence during subway tunneling. Soil Mechanics and Foundation Engineering, 2009, vol. 46, no. 3, p. 117-119

40. Strokova L.A., Dutova E.M., Ermolaeva A.V., Alimova I.N., Strelnikova A.B. Karst hazard assessment in the design of the main gas pipeline (South Yakutia). IOP Conference Series: Earth and Environmental Science, 2015, vol. 27, article number 012032. Available at: http://iopscience.iop.org/article/10.1088/17551315/27/1/012032 (accessed 10 June 2021).

41. Ghorbanzadeh O., Feizizadeh B., Blaschke T. An interval matrix method used to optimize the decision matrix in AHP technique for land subsidence susceptibility mapping. Environmental Earth Sciences, 2018, vol. 77. Article number 584. Available at: https://doi.org/10.1007/s12665-018-7758-y (accessed 16 June 2021).

42. Gudiyangada Nachappa T., Tavakkoli Piralilou S., Ghorbanzadeh O., Shahabi H., Blaschke T. Landslide susceptibility mapping for Austria using geons and optimization with the Dempster-Shafer theory. Applied Sciences, 2019, vol. 9 (24), article number 5393. Available at: https://doi.org/10.3390/app9245393 (accessed 16 June 2021).

43. Gudiyangada Nachappa T., Kienberger S., Meena S.R., Hölbling D., Blaschke T. Comparison and validation of per-pixel and object-based approaches for landslide susceptibility mapping. Geomatics, Natural Hazards and Risk, 2020, vol. 11, no. 1, pp. 572-600. Available at: https://doi.org/10.1080/19475705. 2020.1736190 (accessed 16 June 2021).

44. Guzzetti F., Reichenbach P., Ardizzone F., Cardinali M., Galli M. Estimating the quality of landslide susceptibility models. Geomorphology, 2006, vol. 81, pp. 166-184. DOI: 10.1016/ j.geomorph.2006.04.007

45. Ivanova E. Landslide susceptibility mapping using Frequency Ratio and Analytic Hierarchy Process (AHP): comparative study of two areas in Bulgaria. Proceedings of the International Conference Analysis and Management of Changing Risk for Natural Hazards. Padua, Italy, 18-19 November, 2014. pp. AP23-1- 
AP23-9. Available at: https://www.researchgate.net/publication/ 318589814 (accessed 16 June 2021).

46. Rasyid A.R., Bhandary N.P., Yatabe R. Performance of frequency ratio and logistic regression model in creating GIS based landslides susceptibility map at Lompobattang Mountain, Indonesia. Geoenvironmental Disasters, 2016, vol. 3, article number 19. Available at: https://doi.org/10.1186/s40677016-0053-x (accessed 16 June 2021).

47. Zhang Y.X., Lan H.X., Li L.P. Optimizing the frequency ratio method for landslide susceptibility assessment: A case study of the Caiyuan Basin in the southeast mountainous area of China. Journal of Mountain Science, 2020, vol. 17, article number 2. Available at: https://doi.org/10.1007/s11629-019-5702-6 (accessed 16 June 2021)

48. Zhuang J., Peng J., Zhu X. Spatial distribution and susceptibility zoning of geohazards along the Silk Road, XianLanzhou. Environmental Earth Sciences, 2016, vol. 75 Article number 711. Available at: https://doi.org/10.1007/s12665016-5428-5 (accessed 16 June 2021).

49. Lee S., Thalib J. A. Probabilistic landslide susceptibility and factor effect analysis. Environmental Geology, 2005, vol. 47, pp. 982-990. Available at: https://doi.org/10.1007/s00254-005-1228-z (accessed 16 June 2021)

50. Saaty T.L. The Analytic Hierarchy Process: planning, priority setting, resource allocation. New York, NY, Mcgraw-Hill, 1980. $361 \mathrm{p}$.

51. Linden A. Measuring diagnostic and predictive accuracy in disease management: An introduction to receiver operating characteristic (ROC) analysis. Journal of Evaluation in Clinical Practice, 2006 vol. 12, pp. 132-139. DOI: 10.1111/j.1365-2753.2005.00598.x

52. Chai M., Li G., Ma W., Cao Y., Wu G., Mu Y., Du Q. Assessment of freeze-thaw hazards and water features along the China-Russia crude oil pipeline in permafrost regions. Remote Sensing, 2020, vol. 12 , no. 21 , pp. 35-76.

53. Chen F., Zhou R., Van de Voorde T., Chen X., Bourgeois J., Gheyle W., Goossens R., Yang J., Xu W. Automatic detection of burial mounds (kurgans) in the Altai Mountains. Journal of

\section{Information about the authors}

Lyudmila A. Strokova, Dr. Sc., professor, National Research Tomsk Polytechnic University.

Yulia Y. Nadezhdina, postgraduate student, National Research Tomsk Polytechnic University.
Photogrammetry and Remote Sensing, 2021, vol. 177, pp. $217-$ 237.

54. Vysotsky E.M., Novikov I.S., Lunina O.V., Agatova A.R., Nepop R.K. Coseismic surface ruptures of the 2003 Chuya Earthquake (Gorny Altai): slip geometry and spatial patterns. Russian Geology and Geophysics, 2021, vol. 62, no. 3, pp. 278-290. DOI: https://doi.org/10.2113/RGG20194133

55. Franklin S.E. Interpretation and use of geomorphometry in remote sensing: a guide and review of integrated applications. International Journal of Remote Sensing, 2020, vol. 41, no. 19, pp. 7700-7733.

56. Lemieux J.M., Fortier R., Murray R., Dagenais S., Cochand M., Delottier H., Parhizkar M. Groundwater dynamics within a watershed in the discontinuous permafrost zone near Umiujaq (Nunavik, Canada). Hydrogeology Journal, 2020, vol. 1, pp. 1-19.

57. Lim M., Whalen D., Martin J., Mann P.J., Hayes S., Fraser P. Massive ice control on permafrost coast erosion and sensitivity. Geophysical Research Letters, 2020, vol. 47, e2020GL087917. Available at: https://doi.org/10.1029/2020GL087917 (accessed 16 June 2021)

58. SSerban R.-D., Jin H., Șerban M., Luo D., Wang Q., Jin X., Ma Q. Mapping thermokarst lakes and ponds across permafrost landscapes in the Headwater Area of Yellow River on northeastern Qinghai-Tibet Plateau. International Journal of Remote Sensing, 2020, vol. 41, no. 18, pp. 7042-7067. DOI: 10.1080/01431161. 2020.1752954

59. Yu W., Zhang T., Lu Y., Han F., Zhou Y., Hu D. Engineering risk analysis in cold regions: State of the art and perspectives. Cold Regions Science and Technology, 2020, vol. 171, no. 102963.

60. Zhang Y., Olthof I., Fraser R.H., Wolfe S.A. A new approach to mapping permafrost and change incorporating uncertainties in ground condition and climate projections. The Cryosphere, 2014, vol. 8, no. 6, pp. 2177-2194. Available at: https://doi.org/ 10.5194/tcd-8-1895-2014 (accessed 16 June 2021).

Received: 8 July 2021. 